\title{
MEI-1/MEI-2 katanin-like microtubule severing activity is required for Caenorhabditis elegans meiosis
}

\author{
Martin Srayko, ${ }^{1}$ Dan W. Buster, ${ }^{2}$ Omar A. Bazirgan, ${ }^{2}$ Francis J. McNally, ${ }^{2}$ and Paul E. Mains ${ }^{1,3}$ \\ ${ }^{1}$ Department of Biochemistry and Molecular Biology, Genes and Development Research Group, University of Calgary, \\ Calgary, Alberta, T2N 4N1 Canada; ${ }^{2}$ Section of Molecular and Cellular Biology, University of California, Davis, California \\ 95616 USA
}

The Caenorhabditis elegans meiotic spindle is morphologically distinct from the first mitotic spindle, yet both structures form in the same cytoplasm $\sim 20$ minutes apart. The mei-1 and mei-2 genes of C. elegans are required for the establishment of the oocyte meiotic spindle but are not required for mitotic spindle function. mei-1 encodes an AAA ATPase family member with similarity to the p60 catalytic subunit of the heterodimeric sea urchin microtubule-severing protein, katanin. We report that mei-2 encodes a 280 -amino acid protein containing a region similar to the p80-targeting subunit of katanin. MEI-1 and MEI-2 antibodies decorate the polar ends of meiotic spindle microtubules and meiotic chromatin. We find that the subcellular location of MEI-2 depends on wild-type mei-1 activity and vice versa. These experiments, combined with MEI-1 and MEI-2's similarity to p60 and p80 katanin, suggest that the C. elegans proteins function as a complex. In support of this idea, MEI-1 and MEI-2 physically associate in HeLa cells. Furthermore, co-expression of MEI-1 and MEI-2 in HeLa cells results in the disassembly of microtubules. These data lead us to conclude that MEI-1/MEI-2 microtubule-severing activity is required for meiotic spindle organization in $C$. elegans.

[Key Words: Meiotic spindle; katanin; microtubule-severing; AAA protein; Caenorhabditis elegans]

Received February 24, 2000; revised version accepted March 20, 2000.

Faithful chromosome segregation during meiosis and mitosis depends on the assembly of microtubules (MTs) into a bipolar spindle. In most animals, mitotic spindle bipolarity is established by two diametrically opposed centrosomes, which nucleate the spindle MTs (Schatten 1994). On nuclear envelope breakdown, the growing MT ends make physical contact with the kinetochores of chromosomes and become resistant to depolymerization, a process known as search and capture (Kirschner and Mitchison 1986).

For many organisms, female meiotic spindles form in the absence of centrosomes (Sawada and Schatten 1988; Gard 1992; Theurkauf and Hawley 1992; Albertson and Thomson 1993). Instead of nucleating from centrosomes as in mitosis, MTs polymerize initially around the meiotic chromatin (Tournebize et al. 1997). Subsequently, these MTs are organized from the inside out. Chromatinassociated plus end-directed motor proteins such as chromokinesin (Wang and Adler 1995), Xenopus Xklp1 (Vernos et al. 1995; Walczak et al. 1998) or Drosophila Nod (Afshar et al. 1995) have been implicated in pushing MT-minus ends away from chromatin. The radially symmetric MT array is then focused into two opposing poles, likely by minus end-directed motors with MT-tethering

${ }^{3}$ Corresponding author.

E-MAIL mains@ucalgary.ca; FAX (403) 270-0737. properties [e.g., Eg5 (Walczak et al. 1998) or Drosophila Ncd (Matthies et al. 1996)]. Many factors necessary for the establishment of acentrosomal spindles also have been shown to play a role in mitotic spindle assembly (for review, see Merdes and Cleveland 1997; Walczak et al. 1998). However, differences in the morphology, position, and size of meiotic and mitotic spindles suggest that at least some components must be specific. What, then, are the spindle components responsible for specifying the architecture of meiotic versus mitotic spindles?

We previously identified the Caenorhabditis elegans gene mei-1, which encodes an oocyte-specific meiotic spindle component (Clark-Maguire and Mains 1994b). mei-1 loss-of-function (lf) mutations result in disorganized meiotic spindle MTs and meiotic failure, but mitotic spindles are normal (Mains et al. 1990; Clandinin and Mains 1993; Clark-Maguire and Mains 1994a). In contrast, the gain-of-function mutation mei-1(ct46gf) results in normal meiosis followed by aberrant mitosis. Mitotic spindles in mei-1(ct46gf) are shorter than wild type and they are often mispositioned toward the posterior of the one-cell embryo. Molecular characterization of mei-1 showed that the mei-1(ct46gf) phenotype is likely caused by the persistence of an otherwise meioticspecific MEI-1 protein into mitosis (Clark-Maguire and Mains 1994b).

MEI-1 is an AAA ( $\underline{A} T P a s e$ associated with various cel- 
lular activities; for review, see Patel and Latterich 1998| family member (Clark-Maguire and Mains 1994a) that exhibits a high degree of similarity to sea urchin katanin p60 (Hartman et al. 1998). Katanin is a heterodimeric MT-severing protein consisting of p60 and p80 subunits (McNally and Vale 1993). The p60 subunit by itself shows ATP-dependent MT-severing activity; the p80 subunit is likely involved in the subcellular targeting of this severing activity (Hartman et al. 1998). Possible roles for katanin include the disassembly of interphase MTs at the onset of mitosis (Vale 1991; McNally and Thomas 1998), mediation of MT poleward flux at centrosomes (McNally et al. 1996), deflagellation in Chlamydomonas (Lohret et al. 1998), and release of MTs from the centrosome during outgrowth of neuronal processes (Ahmad et al. 1999). The meiotic spindle in C. elegans is much smaller than the first mitotic spindle. This size difference suggests that a katanin-like MEI-1 might function to keep MTs short during meiosis. Similarly, ectopic MEI-1(ct46) severing activity provides a ready explanation for the mitotic spindle phenotypes observed in mei-1(ct46gf) mutants.

We describe the cloning and molecular characterization of mei-2, a gene originally identified as a suppressor of mei-1(ct46gf) (Mains et al. 1990). The MEI-2 protein contains a region of similarity to the p80-targeting subunit of katanin. Previous genetic analysis indicated that mei-2(+) behaves genetically as an activator of mei-1(+) in both meiosis (Mains et al. 1990; Clandinin and Mains 1993; Clark-Maguire and Mains 1994a) and mei-1(ct46gf) mitosis (Clark-Maguire and Mains 1994b). This dependence of mei-1 activity on mei-2 is paralleled by the observation that p60 katanin in vitro severing activity increases in the presence of p80 (Hartman et al. 1998).

The sequence similarities between MEI-1/MEI-2 and katanin p60/p80 suggest that the C. elegans proteins physically interact and sever MTs during meiosis. We present evidence that supports this model. First, MEI-1 and MEI-2 exhibit similar patterns of subcellular location during wild-type oocyte meiosis and these patterns require the presence of both wild-type proteins. Second, mutations that result in the persistence of MEI-1 into mitosis also result in the persistence of MEI-2 into mitosis. Third, a GFP-MEI-1 fusion protein copurifies with GST-MEI-2 from transiently transfected HeLa cells. Finally, expression of these two proteins in HeLa cells results in the disassembly of interphase MTs. Based on these observations, we propose that MEI-1/MEI-2 sever MTs of the meiotic spindle in C. elegans. This novel role for a katanin-like protein may explain how meiotic spindles maintain their small size in a cytoplasmic environment that later supports the assembly of a much larger mitotic spindle.

\section{Results}

\section{Identification and cloning of mei-2}

We used genetic and physical mapping to limit the mei-2 region to three cosmids shown in Figure 1A /see Mate-
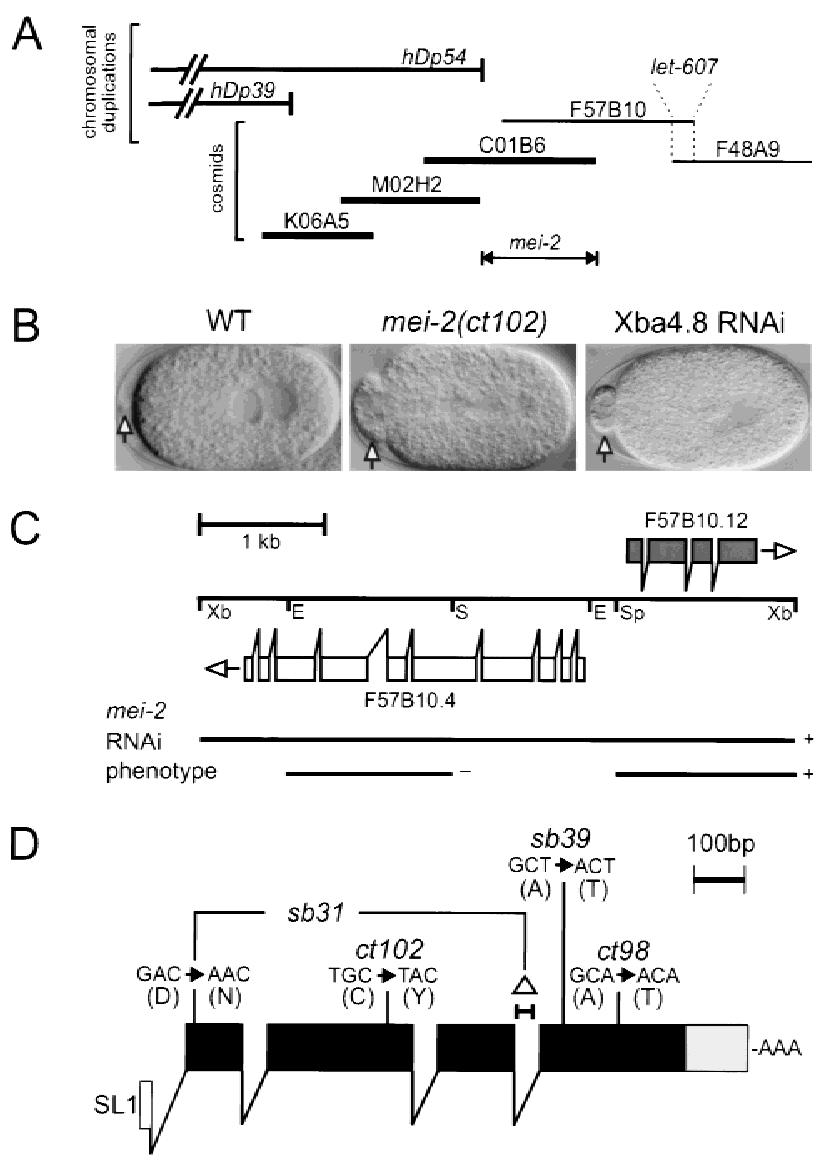

Figure 1. Mapping, RNAi, and sequencing of molecular lesions identifies mei-2. (A) mei-2 was genetically mapped to LGI, 0.016 $\mathrm{cm}(\sim 1 / 2$ the length of a cosmid) to the left of let-607, a gene which we rescued with cosmids F57B10 and F48A9. The duplications $h D p 39$ and $h D p 54$ did not rescue mei-2 mutations. The endpoint of $h D p 54$ was mapped to cosmid C01B6, thus placing mei-2 to the right. Cosmids that rescued the mei-2(ct102) mutation when coinjected are shown in bold. $(B)$ Embryos from hermaphrodites injected with RNA transcribed from a $4.8 \mathrm{~kb} \mathrm{XbaI}$ subclone of cosmid F57B10 (shown in $C$ ) exhibited the mei-2-like phenotype. Note the large polar body in the anterior, compared with wild type (WT) (arrows). (C) To identify the mei-2 gene, RNA was transcribed from three genomic subclones of cosmid F57B10 indicated. RNA transcribed from a SacI-EcoRI subclone containing F57B10.4 (white boxes) did not produce any obvious phenotype. A SpeI-XbaI subclone containing mei-2 (F57B10.12, black boxes) did produce the mei-2 phenotype, identical to the entire XbaI 4.8-kb subclone. (Xb) XbaI; (Sp) SpeI; (E) EcoRI; (S) SacI. (D) The mei-2 structure, as predicted by Genefinder and confirmed by RT-PCR, is shown. mei-2 is trans-spliced to the leader sequence SL1(white box) and encodes four exons (black boxes). The 3' UTR is 122 nucleotides long (grey box). The DNA sequence alterations responsible for each of the four mei-2 mutations are also shown. mei-2(sb31) contains two lesions, one point mutation and a 35-bp deletion $(\triangle)$ that results in an in-frame insertion of four amino acids. The sequence of mei-2 is available from GenBank/EMBL/ DDBJ under accession number AF248052.

rials and Methods). Because germ line transformation rescue was weak, we used RNA-mediated interference (RNAi) (Fire et al. 1991; Guo and Kemphues 1995; Fire et 
al. 1998; Montgomery et al. 1998) to identify mei-2. A mei-2-like phenotype was observed after injection of RNA transcribed from a small subclone that contained the single predicted gene F57B10.12 (Fig. 1B, C; see Materials and Methods).

Additional support for F57B10.12 encoding mei-2 came from an experiment in which the RNA was injected into mei-1(ct46gf) homozygotes. Original mei2(lf) alleles were identified as suppressors of mei1(ct46gf) (Mains et al. 1990) and, as predicted, F57B10.12(RNAi) was also able to suppress mei-1(ct46gf) (data not shown). Together, the RNAi evidence indicated that we had specifically affected a gene that not only produced a mei-2-like phenotype, but also behaved as an If suppressor of mei-1(ct46gf). These results prompted sequencing of each of the four known mei-2 mutants.

RT-PCR was used to confirm the Genefinder predicted structure of mei-2 and all four mutations were identified within the coding region (Fig. 1D and Fig. 2B, see Materials and Methods). mei-2(ct98) is the weakest mei-2 maternal-effect lethal (Mel) mutation with $78 \%$ hatching at the restrictive temperature of $25^{\circ} \mathrm{C}$ (Mains et al. 1990). mei-2(sb39) is a strong ts Mel mutation with $85 \%(978 / 1146)$ hatching at $15^{\circ} \mathrm{C}$, compared to $1.1 \%(8 /$ 758) hatching at $25^{\circ} \mathrm{C}$. mei-2(ct102) (Mains et al. 1990) and mei-2(sb31) are both nonconditional, fully-penetrant Mels. We did not find any obvious correlation between the nature of molecular lesions and mutant phenotypes.

The predicted mei-2 transcript encodes a 280-amino acid protein. A BLAST (Altschul et al. 1990) search with MEI-2 sequence identified the Strongylocentrotus purpuratus katanin p80 subunit $29 \%$ identity and $52 \%$ similarity over 96 amino acids). The region of similarity is restricted to the carboxyl termini of both proteins (amino acids 144-240 for MEI-2 and 559-654 for katanin p80; Fig. 2A). In addition, this search uncovered two predicted C. elegans genes of unknown function, F47G4.4 (GenBank accession no. CAB16313) and F47G4.5 (GenBank accession no. CAB16311). All four proteins share a well-conserved region within the carboxyl terminus (Fig. 2). F47G4.4 is more similar to katanin p80 than the other

A

MEI-2

280

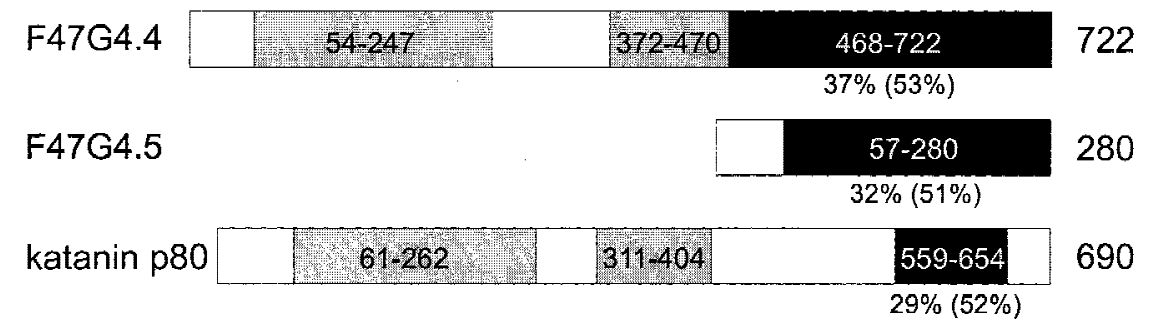

Figure 2. Comparison of MEI-2 and related proteins. (A) Schematic representations of full-length C. elegans MEI-2, F47G4.4, F47G4.5, and $S$. purpuratus katanin $\mathrm{p} 80$ proteins are shown. The region of similarity as determined by BLAST searching with MEI-2 sequence is represented by black boxes containing amino acid coordinates. Percent identity (and similarity in brackets) to MEI-2 are shown below each protein. Two regions of homology between F47G4.4 and katanin p80, as determined from a BLAST search with F47G4.4 are also depicted $28 \%$ identity $/ 51 \%$ similarity for the amino-terminal region, and $23 \%$ identity $/ 37 \%$ similarity for the middle region, grey boxes). (B) Pileup results for MEI-2, F47G4.4, F47G4.5, and katanin p80 are shown. Full-length MEI-2 protein sequence is aligned with the carboxy-terminal portion of F47G4.4, most of F47G4.5, and the carboxyl terminus of katanin p80.

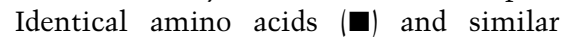
amino acids (grey boxes) to MEI-2 are indicated. Also shown are the positions and nature of molecular lesions found in each mei-2 mutant. $\nabla$ Insertion of four amino acids (FCNS) caused by the 35-bp deletion in mei-2(sb31) (see Fig. 1D). Alignment of sequences was performed with the Genetic Corporation Group (Madison, WI) Pileup program and the freeware program, Boxshade.

B

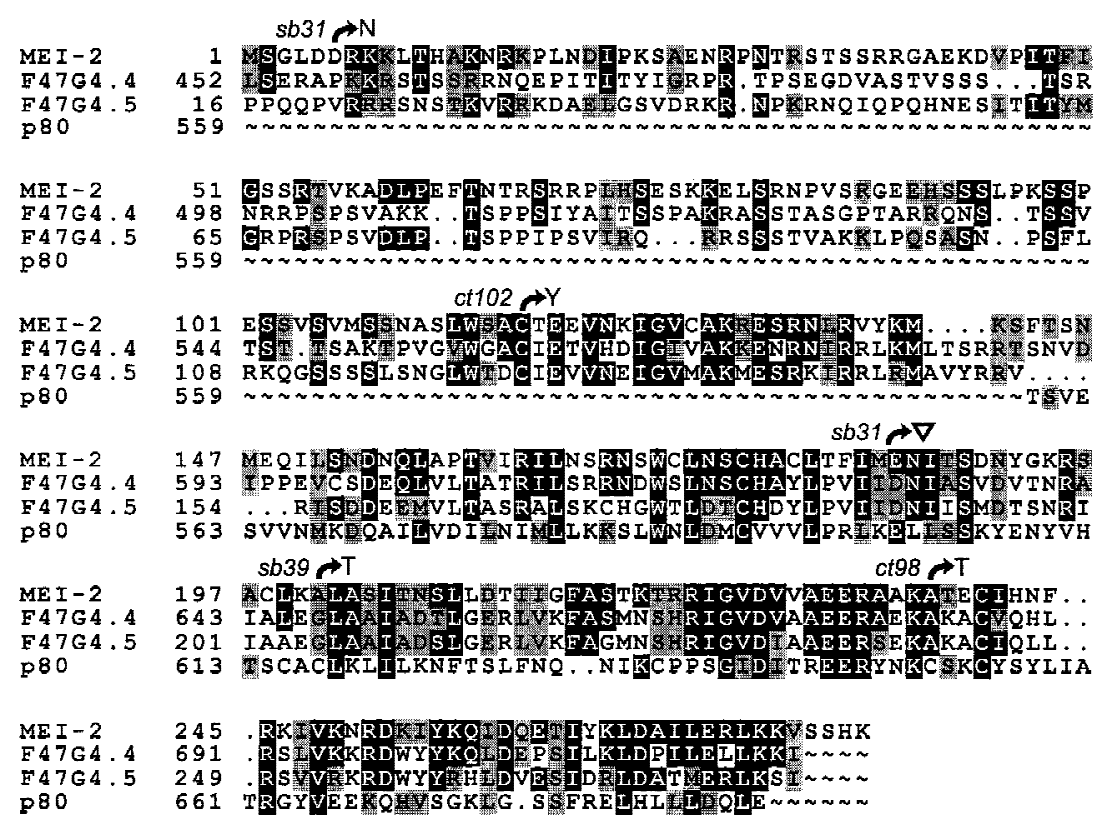


C. elegans proteins, with two additional regions of homology, shown schematically in Figure 2A. The alignment of these proteins is shown in Figure $2 \mathrm{~B}$, along with the positions of mei-2 mutations.

To assess the function of F47G4.4 and F47G4.5, we performed RNAi (see Materials and Methods). We saw no obvious phenotype when dsRNA from either gene was injected individually or together.

\section{Expression of mei-2 $m R N A$ and protein}

mei-2 mutations exhibit strict maternal-effect lethality (Mains et al. 1990). Therefore, it is likely that the mei-2 product is provided by the female germ line. To test this, we measured the levels of mei-2 mRNA and protein at different stages of development and in three different germ-line-defective mutants. A Northern probed with a subclone containing the mei-2 gene revealed a single transcript of $950 \mathrm{bp}$ (Fig. 3A), consistent with our results from RT-PCR analysis. As expected, mei-2 expression was highest in the gravid adult stage, with very low levels present in L1 and L4 larval stages. Expression was reduced severely, but not absent in mutants that fail to make a germ line (glp-1; Austin and Kimble 1987), suggesting that the majority of mei-2 expression was indeed derived from germ line tissue. A strong signal was observed in mutants that make oocytes, but not sperm [fem-1(hc17); Nelson et al. 1978], indicating strong expression in female germ line; however, mei-2 was also expressed in mutants that make sperm but not oocytes [fem-3(q20); Barton et al. 1987]. Since mei-2 mutants result in a strict maternal-effect lethal phenotype, transcription in the hermaphrodite male germ line was unexpected (see below).

Antibodies to full-length bacterially expressed MEI-2 protein were affinity purified with an amino-terminal portion of MEI-2 (see Materials and Methods) and used to probe Western blots of wild-type and mutant worm lysates. A single band of $\sim 33 \mathrm{kD}$ was observed, consistent with the predicted size for MEI-2 (32 kD). The intensity of this band was greatly reduced in fem-3(q20) (spermonly mutant), indicating maternal expression of the protein (Fig. 3B) despite the presence of mei-2 transcript in both male and female germ lines as depicted in Figure 3A. As expected, MEI-2 expression was high in the fem1(hc17) (oocytes-only) mutant worm lysate. Immunoreactivity with each mei-2 mutant was consistently lower than with wild type [especially for mei-2(sb31)], suggesting decreased accumulation of mutant forms of MEI-2. The MEI-2(sb31) protein migrated consistently slower ( $0.5 \mathrm{kD}$ larger than wild type), confirming that the mutation results in a net increase of four amino acids. This altered migration of MEI-2(sb31) also confirmed the specificity of this antiserum for MEI-2 on Western blots.

\section{Immunolocation of MEI-2 in meiotic embryos}

To determine the subcellular location of the MEI-2 protein, affinity-purified MEI-2 antiserum was applied to
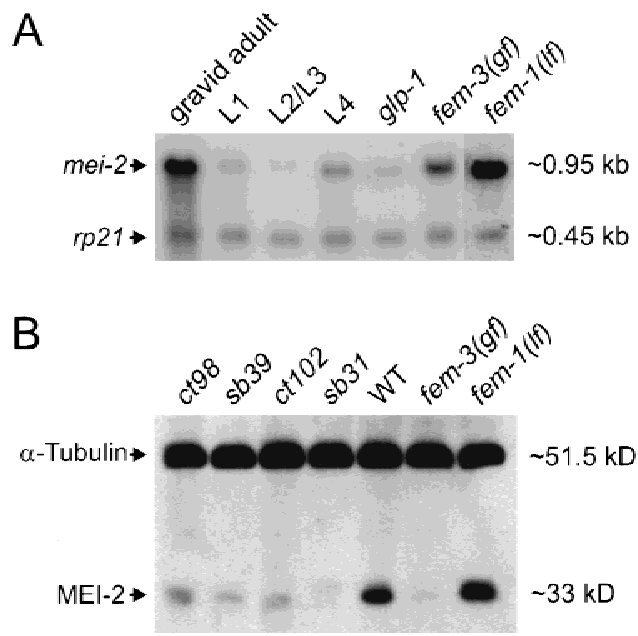

Figure 3. Expression of mei-2 mRNA and protein. (A) Northern blot analysis of mei-2 mRNA. Poly $\mathrm{A}^{+}$RNA was loaded into each lane and probed with a genomic clone containing mei-2 (see Materials and Methods). RNA was harvested from gravid wild-type hermaphrodites, larval stages L1, L2/L3, L4, as well as glp-1 hermaphrodites (lacking a germ line), fem-3 adults (which produce sperm, but not oocytes), and fem-1 adults (which do not produce sperm, and tend to bloat with unfertilized oocytes). As a loading control, the blot was probed simultaneously with $r p 21$, a ribosomal protein gene. fem-1(lf) lane exposure was adjusted until the $r p 21$ signal was approximately equal to the signal in other lanes. (B) Western blot analysis of MEI-2. Homogenates prepared from mei-2 mutant hermaphrodites, wild type, $f e m-3$, and fem-1 were probed with anti-MEI-2 serum. Note the slightly retarded migration of $\mathrm{MEI}-2(s b 31)$ protein, consistent with the net insertion of four amino acids. As a loading control, the blot was probed simultaneously with anti- $\alpha$-tubulin.

dissected wild-type worms and embryos. MEI-2 was detected throughout the cytoplasm of the most mature oocytes within the proximal gonad (Fig. 4A). In fertilized embryos, anti-MEI-2 decorated the condensed chromatin and spindle poles of meiosis I and II, as well as the condensed sperm pronucleus and polar bodies (Fig. 4B,E). Female meiotic chromatin staining persisted throughout metaphase (Fig. 4E), anaphase, and telophase (data not shown). With the exception of the polar body staining, anti-MEI-2 was not observed in post-meiotic embryos (Fig. 6C, see below).

mei-2 mutant embryos were also stained with antibodies to MEI-2 (Fig. 5). In all mei-2 mutants, female meiotic chromosomes condensed normally and were located near the zygote anterior, indicating that MEI-2 does not play a major role in chromosome condensation. However, strong mei-2 mutants displayed paired chromosomes that were not aligned on a metaphase plate. Embryos mutant for the genetically weak allele mei-2(ct98) had slightly disorganized spindles, but still exhibited MEI-2 staining in a pattern similar to wild type (Fig. 5E, F). All staining (including oocyte cytoplasm, chromatin, polar bodies, and sperm pronucleus) was identical to wild type, albeit at reduced intensity (data not shown). The strong, nonconditional mutant mei-2(ct102), dis- 


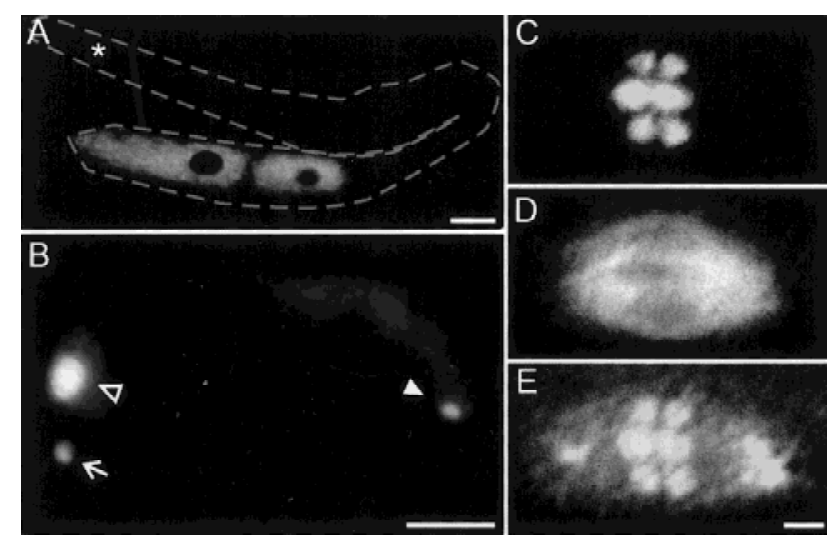

Figure 4. Immunolocation of MEI-2. (A) MEI-2 expression was first apparent in the proximal gonad of adult hermaphrodites. Typically, the last 2-3 oocytes in this region stained with antiMEI-2. MEI-2 was not observed in the distal portion of the gonad $\left({ }^{\star}\right)$, where mitotic proliferation of germ cells occurs. A dotted line indicates the outline of one gonad arm (as determined by Nomarski microscopy and DAPI immunofluoresence, not shown). (B) An embryo undergoing meiosis II is shown. MEI-2 antiserum decorated the meiotic spindle and condensed meiotic chromatin (clear arrowhead), the polar body from meiosis I (arrow) and the condensed sperm pronucleus (white arrowhead). Anti-MEI-2 also stained the meiosis-I spindle and polar body from meiosis II (not shown). With the exception of the polar bodies, all MEI-2 staining disappeared after the completion of meiosis (see Fig 6C). (C-E) Deconvolution imaging of a meiotic spindle in metaphase is shown, stained with $(C)$ DAPI, to visualize chromatin, $(D)$ anti- $\alpha$-tubulin, and $(E)$ anti-MEI-2. The MEI-2 staining patterns were also documented in the absence of DAPI and $\alpha$-tubulin staining (data not shown), to ensure that the observed patterns did not result from artifacts of multichannel fluorescence microscopy. Bars: $A$ and $B 10 \mu \mathrm{m} ; E 1 \mu \mathrm{m}$.

played severely disorganized meiotic spindles that lacked bipolarity, and all MEI-2 staining was absent (Fig. $5 \mathrm{H}-\mathrm{I})$. This also was observed for mei-2(sb31) (not shown). These results indicate that MEI-2 is required for meiotic spindle MT organization and that strong mei-2 mutations disrupt the localization of MEI-2 and/or reduce the amount of MEI-2 below our limit of detection via immunohistochemistry.

\section{MEI-2 localization requires MEI-1}

To determine if MEI-2 protein localization was dependent on mei-1 activity, we looked for the presence of MEI-2 in three mutant backgrounds: mei-1(ct101)—a null mutant, mei-1(ct82)—a dominant negative, and mei-1(ct46gf). Meiotic spindles were disorganized in mei-1(ct101) and mei-1(ct82) mutants. Chromatin, spindle poles, polar bodies, and the sperm pronucleus failed to stain with anti-MEI-2 (data not shown). Thus, either mei-1 $(+)$ or an intact meiotic spindle is required for the localization of MEI-2 during meiosis. As a further test of the dependence of MEI-2 localization on MEI-1, we examined mei-1(ct46gf) embryos. Because mei1 (ct46gf) results in ectopic MEI-1 at mitotic spindles
(Clark-Maguire and Mains 1994b), we tested for the presence of MEI-2 during mitosis in these mutant embryos. Indeed, ectopic MEI-2(+) staining was also observed during mitosis in the mei-1(ct46gf) mutant background (Fig. 6D-I). Specifically, anti-MEI-2 was detected within the MT-free zone at the center of the centrosomes and with condensed mitotic chromatin from metaphase to anaphase, in a pattern identical to MEI-1 (see below and Fig. 7).

mel-26(ct61), a post-meiotic negative regulator of mei1 , causes mitotic defects identical to mei-1(ct46gf) as a result of ectopic MEI-1(+) persistence into mitosis (Clark-Maguire and Mains 1994b; Dow and Mains 1998). The ectopic MEI-2 staining pattern observed in mei1(ct46gf) embryos was also observed in mel-26(ct61) embryos (data not shown). In addition, we used anti-MEI-2 to immunostain mei-1(ct101) mel-26(ct61) double mutant embryos, which show meiotic, but not mitotic defects (Clark-Maguire and Mains 1994b). No MEI-2 staining was observed, indicating that the mislocalization of MEI-2 in mel-26(ct61) embryos also depended on the presence of wild-type MEI-1 (data not shown).

We reported previously that MEI- 1 locates to the female meiotic spindle MTs, the polar bodies, the condensed sperm pronucleus, and the condensed meiotic chromatin during telophase (Clark-Maguire and Mains 1994b). However, antibodies to MEI-2 also stain meiotic metaphase chromatin, which we did not observe previously with anti-MEI-1. The original MEI-1 experiments were performed with crude antisera, so we reexamined MEI-1's intracellular distribution with affinity-purified antiserum. With this new reagent, we observed staining of meiotic chromatin in wild-type embryos, and mitotic chromatin staining in mei-1(ct46gf) in a pattern identical to MEI-2 (Fig. 7), along with all previously reported

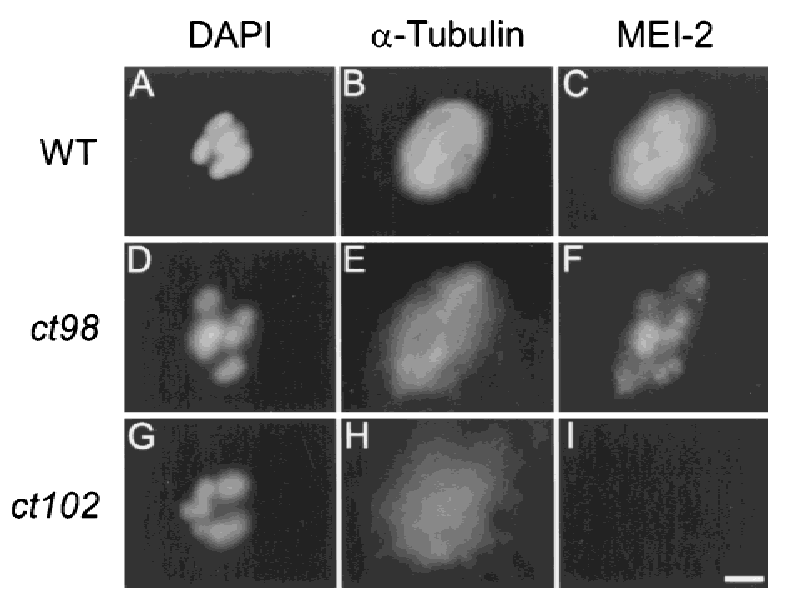

Figure 5. MEI-2 immunolocation in mei-2 mutants. Meiotic spindles from wild-type (WT; $A-C$ ) and mei-2 mutant embryos $(D-I)$ were fixed and stained with DAPI $(A, D, G)$ anti- $\alpha$-tubulin $(B, E, H)$ and anti-MEI-2 $(C, F, I)$. ct98 and $c t 102$ are mei-2 alleles (top-down is in order of increasing genetic severity). The ts allele mei-2(ct98) was grown at the restrictive temperature of $25^{\circ} \mathrm{C}$. Bar; $2 \mu \mathrm{m}$. 


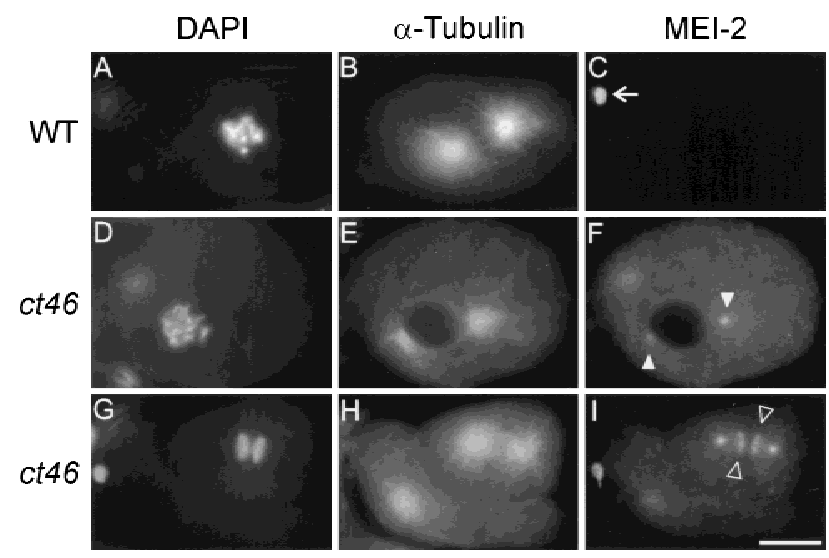

Figure 6. Mislocalization of MEI-2 to mitotic chromatin and centrosomes in mei-1(ct46gf) mutant embryos. Wild-type (WT; $A-C)$ and mei-1(ct46gf) $(D-I)$ mutant embryos were fixed and stained with DAPI $(A, D, G)$, anti- $\alpha$-tubulin $(B, E, H)$, and antiMEI-2 $(C, F, I)$. All meiotic staining of MEI-2 appeared normal in both wild-type and mei-1(ct46gf) embryos (not shown). (A-C) Wild-type embryo in first mitosis showed no MEI-2 staining other than the polar bodies (arrow). (D-I) mei-1(ct46gf) embryos exhibited centrosomal staining during prometaphase $(F)$, and centrosomal and chromatin staining during metaphase (see Fig. 7D) and anaphase $(I)$. The centrosomal and mitotic chromatin staining patterns reiterated for several divisions. We also observed the same staining pattern in mel-26(ct61) mutant embryos (not shown). Bar; $10 \mu \mathrm{m}$.

staining patterns, indicating that MEI-1 and MEI-2 have an identical intracellular distribution.

We also wanted to test whether MEI-2 staining patterns were altered in a zyg-9 mutant background. zyg-9 mutations exacerbate the mitotic defects associated with mei-1(ct46gf) but do not interact genetically with mei-1(lf) or any mei-2 mutations (Kemphues et al. 1986; Mains et al. 1990). We reported previously that antiMEI-1 staining is unaltered in a zyg-9(b244) background (Clark-Maguire and Mains 1994b). If MEI-1 and MEI-2 require each other for their activity and/or localization, we should likewise see no change in the MEI-2 staining patterns. As predicted, we were unable to detect any differences in the location of MEI-2 in zyg-9(b244) mutant embryos (data not shown). Therefore, the mitotic-defect enhancement by zyg-9 is not likely due to increasing amounts of MEI-2 (or MEI-1) protein in mitosis.

\section{MEI-2, F47G4.4, and F47G4.5 associate specifically} with $M E I-1$

If MEI- 1 and MEI-2 are functional homologs of p60 and p80 katanin respectively, then these proteins should associate physically with each other as do p60 and p80 katanin. To test this association model, a green fluorescent-protein fusion to MEI-1 (GFP-MEI-1) and a glutathione-S-transferase fusion to MEI-2 (GST-MEI-2) were coexpressed in HeLa cells by transient transfection. GST-MEI-2 and associated proteins were then isolated by glutathione-sepharose chromatography followed by immunoblotting with anti-GST and anti-GFP antibodies. We found that GST-MEI-2 was capable of binding GFP-MEI-1 (Fig. 8A,B, lane 1), but not human p60 katanin, nor the unrelated AAA enzyme VPS4 (Babst et al. 1997) (Fig 8A,B, lanes 4, 5). The association between MEI-1 and MEI-2 was specific because GST alone or a carboxy-terminal portion of human p80 katanin similar to MEI-2 (GST-con80) (McNally et al. 2000) were unable to bind GFP-MEI-1 (Fig. 8A,B, lanes 2, 3). However, this carboxy-terminal human $\mathrm{p} 80$ portion is capable of binding its normal p60 partner (Fig. 8A,B, lane 6). These results indicate that MEI-1 and MEI- 2 can form a complex similar to the p60/p80 katanin dimer. GST fusions to the mei-2-related F47G4.4 and F47G4.5 ORFs also associated with GFP-MEI-1 (Fig. 8A,B, lanes 7, 8) but not with GFP-p60 (data not shown). Therefore, it is possible that these genes encode alternative dimerization partners for MEI-1.

\section{MEI-2 potentiates MEI-1-mediated MT disassembly}

To determine whether MEI-1 has MT disassembly activity like katanin, the MT cytoskeleton in GFP-MEI-1-expressing HeLa cells was examined by anti-tubulin immunofluorescence. In this assay, which has been used as a convenient way to measure in vivo MT-severing by katanin (McNally et al. 2000), MT disassembly is observed as a reduction in overall antitubulin immunofluorescence. In mammalian cells undergoing MT depolymerization, the tubulin subunits are eventually degraded but not replaced due to negative regulation /Cleveland et al. 1981).

When GFP-MEI-1 and GST-MEI-2 were coexpressed in HeLa cells, we frequently observed a dramatic 90-95\% reduction in the intensity of antitubulin immunofluorescence, relative to neighboring untransfected cells (Fig. 9A). To quantify this effect, the intensity of antitubulin staining was plotted against the intensity of GFP fluorescence for a large number of cells (see Materials and

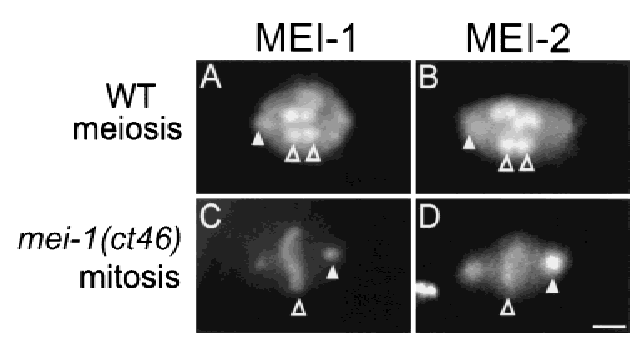

Figure 7. MEI-1 and MEI-2 immunolocation. Spindles from wild-type (WT) and mei-1(ct46gf) mutant embryos were fixed and immunostained with anti-MEI-1 $(A$ and $C)$ and anti-MEI-2 $(B$ and $D)$. In wild type $(A$ and $B)$, MEI- 1 and MEI- 2 were found at meiotic spindle poles (out of focal plane, white arrowheads) and chromatin (clear arrowheads). In mei-1(ct46gf) (C and $D)$, MEI- 1 and MEI-2 were found at centrosomes (white arrowheads) and chromatin (clear arrowheads). Bar; $2 \mu \mathrm{m}$. Embryos in $C$ and $D$ have approximately 10 cells; a close-up of one metaphase spindle from each embryo is shown. 
Srayko et al.
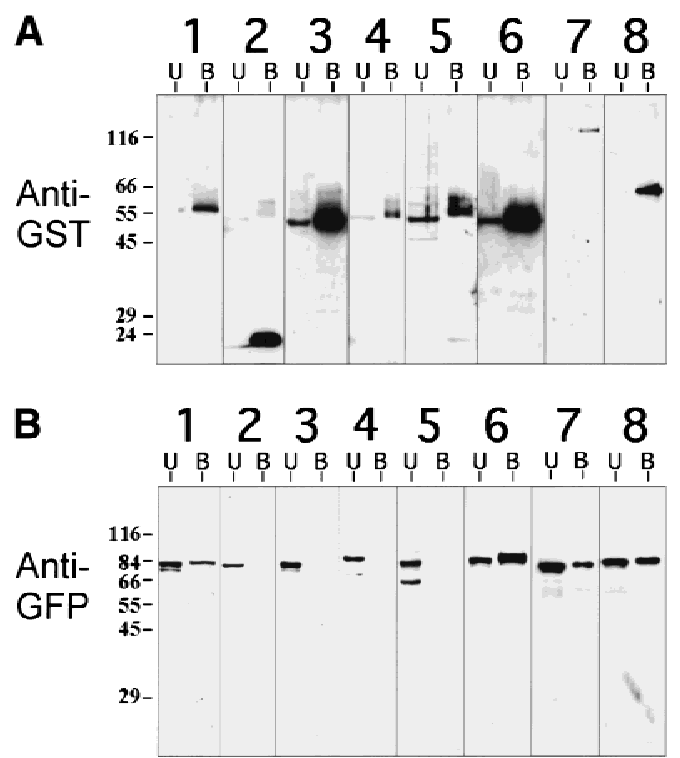

Figure 8. In vivo binding of GFP-MEI-1 with cotransfected GST fusions of MEI-2 and homologs. HeLa cells were cotransfected with GFP-MEI-1 and various GST fusion proteins and were subsequently lysed. GST fusion proteins, along with associated proteins, were isolated by glutathione-sepharose chromatography. The presence of transfected proteins in the glutathione-sepharose bound fraction (B) and unbound fraction (U) was monitored by immunoblotting. (A) Anti-GST-probed immunoblots. HeLa cells were cotransfected with GFP-MEI- 1 and GST-MEI-2 (lane 1), GFP-MEI-1 and GST (lane 2), GFP-MEI-1 and GST-con80 (lane 3), GFP-p60 and GST-MEI-2 (lane 4), GFPVPS4 and GST-MEI-2 (lane 5), GFP-p60 and GST-con80 (lane 6), GFP-MEI-1 and GST-F47G4.4 (lane 7), or GFP-MEI-1 and GSTF47G4.5 (lane 8). (B) Anti-GFP probed immunoblots loaded identically as those in $A$. Positions of standards and their molecular weights (in $\mathrm{kD}$ ) are indicated to the left of each panel.

Methods). As shown in Figure 9B,C, a relatively low basal level of microtubule depolymerization occurred in HeLa cells coexpressing GFP-MEI-1 and either GST alone or GST-con80 (MT ratio of 0.5-1.0). Of note is the fact that almost none of these cells exhibit a MT ratio under 0.5 (which represents a 50\% reduction in antitubulin fluorescence; the broken line is included for ease of comparison between panels B-G). In contrast, many cells coexpressing GFP-MEI-1 and GST-MEI-2 exhibited antitubulin staining intensities that were only $5-20 \%$ of untransfected control cells (MT ratios of 0.05-0.2) (Fig. 9D). Cells coexpressing GST-MEI-2 and a GFP fusion to the AAA enzyme VPS4 did not show MT-disassembly (Fig. 9E), indicating that both MEI-1 and MEI-2 are essential for this effect. These results show that the association of MEI-1 and MEI-2 results in effective MT disassembly.

If the F47G4.4 or F47G4.5 gene products represent alternative p80-like binding partners for MEI-1, then these proteins might also stimulate MEI-1's MT disassembly activity. Analysis of antitubulin staining intensity in HeLa cells cotransfected with GFP-MEI-1 and either GST-F47G4.4 or GST-F47G4.5 indicated that they were as effective as MEI-2 in potentiating MEI-1 activity (Fig. $9 F, G)$.

\section{Discussion}

mei-2 was identified originally as a dominant suppressor of the mitotic-defective gain-of-function mutation mei1(ct46gf) (Mains et al. 1990). The homozygous recessive mei-2(lf) phenotype is identical to the mei-1(lf) phenotype: aneuploidy resulting from failure to assemble normal meiotic spindles (Mains et al. 1990). Like mei-1(lf) embryos, the mei-2(lf) embryos either fail to extrude polar bodies or they form extremely large polar bodies (see Fig. 1B). Meiotic-defective mutations in mei-1 and mei-2 enhance each other with respect to these phenotypes, indicating that these two genes are required for the same process (Clandinin and Mains 1993). The fact that de-
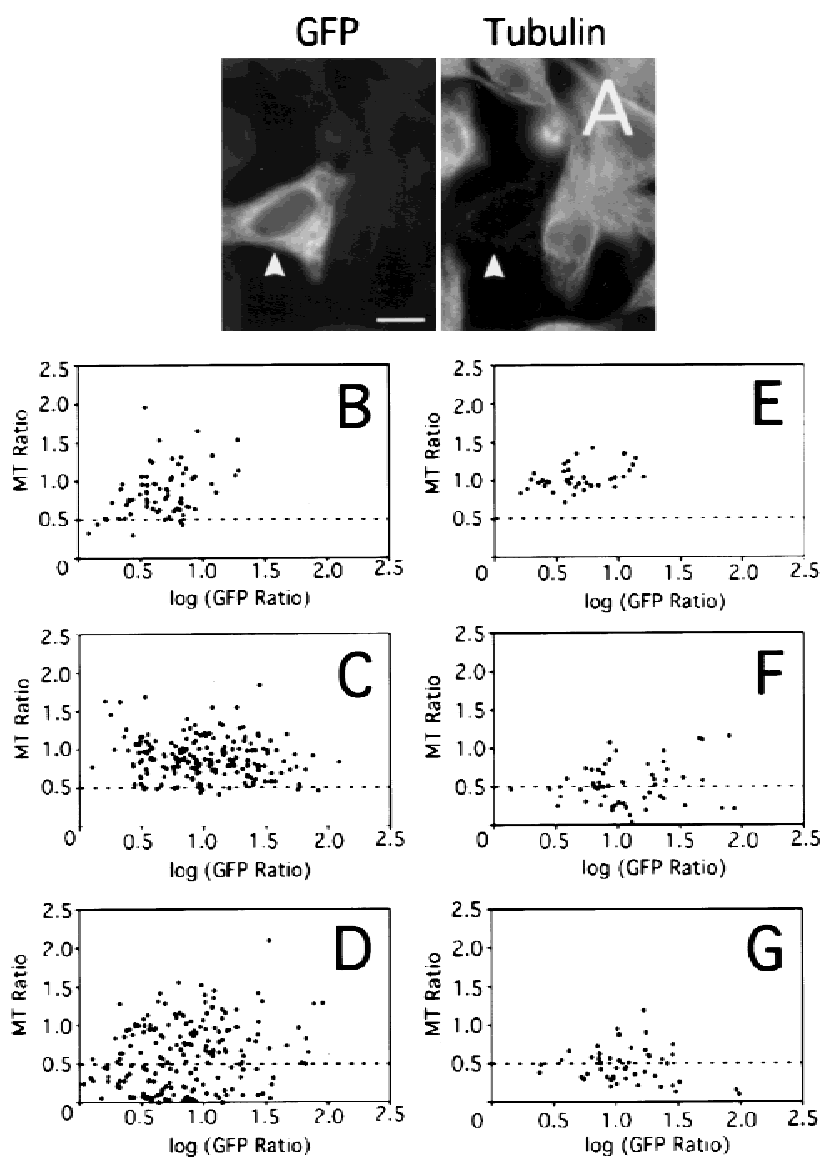

Figure 9. Reduction in the intensity of anti-tubulin immunofluorescence in HeLa cells cotransfected with GFP-MEI-1 and GST fusions of MEI-2 and homologs. (A) Fluorescence micrographs of a HeLa cell coexpressing GFP-MEI-1 and GST-MEI-2 (arrowhead). The intensity of antitubulin staining of the MEI1-expressing cell is reduced relative to that of adjacent untransfected cells, indicating that MT disassembly has occurred. Bar; $10 \mu \mathrm{m} .(B-G)$ The ratio of the antitubulin fluorescence intensity of individual transfected cells to that of neighboring untransfected cells (MT Ratio) was measured and plotted as a function of the GFP-fluorescence ratio of the same cells (GFP Ratio). HeLa cells were cotransfected with $(B)$ GFP-MEI-1 and GST, $(C)$ GFP-MEI-1 and GST-con80, $(D)$ GFP-MEI-1 and GST-MEI-2, (E) GFP-VPS4 and GST-MEI-2, (F) GFP-MEI-1 and GSTF47G4.4, or (G) GFP-MEI-1 and GST-F47G4.5. 
creased mei-2 activity suppresses the mitotic defects caused by ectopic MEI-1 in both mei-1(ct46gf) and mel26(ct61) mutants indicates that mei-2 is required for mei-1(+) activity. mel-26 encodes a novel protein and functions as a postmeiotic negative regulator of mei-1 (Clark-Maguire and Mains 1994b; Dow and Mains 1998).

We identified the mei-2 gene by a combination of genetic mapping, positional cloning, and RNAi (Fig. 1A-C). The generation of MEI-2-specific antiserum allowed a direct comparison of the staining patterns of MEI-1 and MEI-2. Consistent with the known genetic behavior of these genes, we found that MEI-1 and MEI-2 both reside at the chromatin and poles of meiotic spindles in wildtype embryos (Fig. 7). Both proteins seem dependent on each other for their localization because mei-1(lf) mutants abrogate the localization of MEI-2 (this paper) and vice versa (Clark-Maguire and Mains 1994b). From these results, it is not possible to know whether this colocalization is direct or indirect, because proper meiotic spindles do not form in either mei-1 or mei-2 mutant embryos. However, in mutant embryos that have an altered distribution of MEI-1 protein [as in mei-1(ct46gf) and mel-26(ct61)], we always observe concomitant ectopic MEI-2 in an identical pattern (Figs. 6 and 7). In support of a direct-interaction model where MEI-1 and MEI-2 function as a complex during C. elegans meiosis, we found that MEI-1 and MEI-2 copurify from HeLa cell extracts.

\section{MEI-1/MEI-2 sever MTs in HeLa cells}

The finding that coexpression of MEI-1 and MEI-2 in HeLa cells results in a MT-disassembly phenotype (Fig. 9) identical to that observed for katanin (McNally et al. 2000) indicates that MEI-1/MEI-2 has katanin-like MTdisassembly activity. The sea urchin protein katanin is a p60/p80 heterodimer that exhibits MT-severing activity in vitro (McNally and Vale 1993). Although the biological role of katanin is not clear, its presence at spindle poles in sea urchins and mammalian cells suggests a role in disassembling MTs near their minus ends during poleward flux (McNally et al. 1996; McNally and Thomas 1998). The catalytic p60 subunit of katanin is a member of the AAA family of ATPases that exhibits a high degree of similarity to MEI-1, although this similarity does not extend beyond the AAA domain (Hartman et al. 1998). The p80 subunit of katanin contains a WD-40-rich amino terminus that has been implicated in targeting the katanin heterodimer to centrosomes (Hartman et al. 1998). We found that katanin p80 and MEI-2 share a conserved region in their carboxyl termini $(29 \%$ identity over 96 amino acids). This region of $\mathrm{p} 80$ has been implicated in physically interacting with p60 (Hartman et al. 1998). The carboxy-terminal similarity may represent conservation of a protein-protein interaction domain between katanin p60/p80 and MEI-1/MEI-2 and, by implication, a conservation of function between these protein pairs.

Katanin is found in sea urchin embryos and cultured mammalian cells undergoing mitosis (McNally et al. 1996; McNally and Thomas 1998). Unlike katanin,
MEI-1 and MEI-2 have no function during wild-type mitosis but they are essential for meiosis. In fact, MEI-1 and MEI-2 persistence into mitosis [as in mei-1(ct46gf) and mel-26 mutants] is clearly disastrous. Despite these differences, the presence of MEI-1 and MEI-2 at mitotic centrosomes in mei-1(ct46gf) and mel-26 mutants is strikingly reminiscent of katanin's in vivo location. Perhaps MEI-1/MEI-2 represents a specialized katanin that functions within the acentriolar environment of the meiotic spindle. MT disassembly exhibited by GFPMEI-1 and either GST-F47G4.4 or GST-F47G4.5 raises the possibility that MEI-1 may associate with these mei-2 homologs in the worm, possibly for developmental processes distinct from those involving MEI-2.

Does MEI-1/MEI-2 function to sever MTs of the meiotic spindle, as suggested by their activity in HeLa cells? Observations of mutants that result in ectopic mitotic MEI-1 activity [mei-1(ct46gf) and mel-26(ct61)] suggest that MEI-1/MEI-2 can shorten MTs in C. elegans. For instance, such mutants can be phenocopied by low doses of the MT-depolymerizing drug nocodazole (Strome and Wood 1983), indicating that the persistence of MEI-1/ MEI-2 into mitosis results in shorter mitotic spindle MTs. Also, mei-1(ct46gf) and mel-26(ct61) mutants are enhanced by If mutations in zyg-9, a gene that encodes a putative MT-stabilizing protein (Matthews et al. 1998). Therefore, loss of a MT-stabilizing protein due to the zyg-9 mutation would be expected to enhance renegade mitotic MEI-1/MEI-2-severing activity in the mei1(ct46gf) mutant.

The cytoplasmic environment of the early C. elegans embryo must support both meiotic and early mitotic spindle formation. Unlike the mitotic spindle, the female meiotic spindle is small and juxtaposed to the anterior cortex; polar body extrusion occurs rapidly and without loss of valuable cytoplasm. Meiotic-specific MT-severing activity may contribute to these morphological differences in several ways. One possibility is that MEI-1/MEI-2 prevents astral MTs from forming, thus allowing the meiotic spindle to remain in close proximity to the anterior cortex for polar body extrusion. MEI-1/MEI-2 may also restrict the length of MTs that form around the meiotic chromatin. Longer meiotic spindle MTs may be unable to coalesce into focused spindle poles, explaining our observation that mei-1(lf) and mei-2(lf) mutant spindles lack bipolarity, but still exhibit MT staining around meiotic chromatin. In addition, MT persistence around extruded chromatin could cause the large polar body phenotype in mei-1 and mei-2 mutants. In cases where no polar body is extruded, the rudimentary meiotic spindles may be pushed too far away from the cortex. Another possibility is that MTs nucleated by meiotic chromatin may require a postnucleation-processing step prior to their incorporation into the spindle proper. An analogous katanin-mediated mechanism that allows the release of MTs from neuronal centrosomes is required for proper axonal outgrowth (Ahmad et al. 1999).

One major structural difference between meiotic and mitotic spindles is that the former lack centrosomes. 
Whether all morphological distinctions between these two spindles can be accounted for by the presence or absence of centrosomes is not clear. MEI-1/MEI-2 are the first examples of meiotic-specific components that orchestrate meiotic spindle architecture. The existence of such genes implies that in vivo meiotic spindles do not form simply by default in the absence of centrosomes. Further analysis of genes that interact genetically with mei-1 and mei-2 will likely reveal other factors that are involved in this important aspect of biology.

\section{Materials and methods}

\section{Nematode strains}

C. elegans (var. Bristol) was cultured as described (Brenner 1974). The following worm strains were used in this study: N2 (wild type), CB1072 unc-29(e1072)(I), BW1102 dpy-5(e61) mei2(ct102) unc-29(e1072); sDp2 (I;f), HR19 dpy-5(e61) mei2(ct102) daf-8(e1393); sDp2 (I;f), HR543 mei-2(sb31) unc29(e1072)/hT2[bli-4(e937) let(h661)] (I); ++/hT2 (III), BW1048 mei-2(ct98) unc-29(e1072) (I), HR827 mei-2(sb39) unc29(e1072) (I), JK549 fem-3(q20) dpy-20(e1282) (IV), HR219 fem1(hc17) (IV), BW729 mei-1(ct46) unc-29(e1072) (I), BW944 mei1(ct46ct101) unc-29(e1072)/unc-13(e1091) lin-11(n566) (I); lon2(e678) (X), BW722 zyg-9(b244) (II), JK892 unc36 / unc32(e189) glp-1(q231) (III), HR378 bli-4(e937) let-607(h402) unc37(e262); hDp19 (I;f), HR245 mei-1(ct46ct101) unc-29(e1072) mel-26(ct61) / unc-13(e1091) lin-11(n566) (I); lon-2(e678), BW737 mel-26(ct61) (I). Unless otherwise stated, all homozygous mutant worms used were derived from these strains. mei2(sb31) was isolated in a screen for suppressors of mei-1(ct46) (Clandinin and Mains 1993); mei-2(sb39) was isolated in a screen for revertants of mel-26(ct61) (Dow and Mains 1998). These alleles failed to complement mei-2(ct102) and mapped to the same region of chromosome I.

\section{Genetic mapping and transformation}

mei-2 was mapped genetically to chromosome I, 0.016 map units $(\sim 17 \mathrm{~kb})$ to the left of let-607. Three factor mapping data is available from ACeDB. The chromosomal duplication $h D p 54$ (McKim and Rose 1990) failed to complement the mei-2(ct102) mutation and $h D p 54$ 's right endpoint was physically mapped to C01B6 (and two other overlapping cosmids, T09G11 and T01E9) by a Sall polymorphism. This analysis narrowed down the mei-2 region to cosmids C01B6 and F57B10 (Fig.1A).

For germ line transformation rescue, cosmids were injected at a concentration of $\sim 30-60 \mathrm{ng} / \mathrm{\mu l}$ each, along with pRF4 (Mello et al. 1991), a plasmid containing the dominant marker rol6(su1006) at $100 \mathrm{ng} / \mu \mathrm{l}$. All other methodology pertaining to germ line transformation was as described in Mello et al. (1991). Rescue of mei-2 was achieved by coinjecting wild-type worms with three cosmids: K06A5 (or F14G7), M02H2, and C01B6, and generating stable transgenic lines. + mei-2(ct102) + daf-8 / dpy-5 + unc-29 + males were crossed into five independent transgenic lines and Rol Daf F2 progeny (at $25^{\circ} \mathrm{C}$ ) were downshifted to allow exit from dauer and scored for maternal-effect lethality. Four out of five lines showed maternal rescue of mei-2 [survival of $52 / 6608$ progeny, or $0.8 \%$, compared to $1 / 2676$ $(0.04 \%)$ for Daf, Non-Rol sibling control group]. Using the method described, no single cosmid or pairwise combination of cosmids from this region rescued mei-2(ct102), likely due to poor expression typical of maternally expressed transgenes (Kelly et al. 1997).

\section{$R T-P C R$}

First-strand cDNA was constructed using reagents from the SUPERSCRIPT II (GIBCO BRL) kit. 500 ng of polyA ${ }^{+}$RNA isolated from wild-type gravid adults was used as template and an EcoRIdT primer (5'-GCTGCAGAATTCGTCGAC- $\mathrm{dT}_{\left.(17)^{-} 3^{\prime}\right)}$ was used to prime first-strand synthesis. Subsequent PCR was performed with forward and reverse primers specific for the mei-2 coding region, based on Genefinder predictions found in ACeDB. All reactions confirmed the predicted structure. In addition, bands of expected size were PCR-amplified using an SL1specific primer (Krause and Hirsh 1987) with either of two mei2-specific reverse primers; both bands were excised and sequenced. SL1 is spliced onto the mei-2-coding sequence immediately before the predicted ATG start codon. Reactions containing SL2 (Huang and Hirsh 1989) did not amplify any products with any mei-2 reverse primers. The site of polyadenylation was determined by performing PCR on the above mentioned cDNA using an EcoRI adapter (reverse) primer and either of two different mei-2 forward primers. Upon sequencing, polyadenylation was found 13-bp downstream of the sequence TATAAA /corresponding to nucleotide position 16,365 of cosmid F57B10) contained within the mei-2 3'UTR.

For RNAi of the C. elegans genes F47G4.4 and F47G4.5, RTPCR was used to clone full-length cDNA. Primer sequences were based on Genefinder predictions. F47G4.4 primers used were F47G4-4BF (5'-CGGGATCCATGAAAATTGAAGTGGTA-3') (forward) and F47G4-4XR (5'-CCGCTCGAGCTAGATCTTCTTTAAAAG-3') (reverse). F47G4.5 primers were F47G4-5BF (5'-CGGGATCCATGGCACTAACAAGCGTA-3') (forward) and F47G4-5XR (5'-CCGCTCGAGTCAAATGCTCTTCAATCG-3') (reverse).

\section{Sequencing of mei-2 mutations}

For each mutation, 10 homozygous worms were lysed under standard conditions (Williams 1995). PCR was performed on these mutant templates using primers specific for the mei-2 region. PCR products were extracted from gel slices after electrophoretic separation in $1 \%$ agarose. The DNA was purified with Prep-a-Gene matrix (BioRAD) and sequenced with ABI (Perkin-Elmer) technology by Glenis Wiebe at University Core DNA Services (University of Calgary, Canada). At least two independent PCR reactions were sequenced for each mutant.

\section{Northern analysis}

RNA isolation was carried out on animals that were staged according to the method described in Wood (1988). Adult hermaphrodite strains with temperature-sensitive (ts) mutant germ lines were also included. When grown at the restrictive temperature, $g 1 p-1$ (q231) fail to proliferate their germ line (although a few sperm are made in Glp-1 animals) (Austin and Kimble 1987), fem-3(q20gf) animals make sperm but not oocytes (Barton et al. 1987), and fem-1 (hc17lf) animals make oocytes but not sperm (Nelson et al. 1978). Poly(A) ${ }^{+}$RNA was prepared using the FastTrack mRNA Isolation System (Invitrogen) according to the manufacturer's protocols. $3 \mu \mathrm{g}$ (per lane) of RNA was fractionated by electrophoresis under denaturing conditions as described (Sambrook et al. 1989), transferred to a Hybond-N ${ }^{+}$ membrane (Amersham) and hybridized in $5 \times$ Denhardt's, $5 \times$ SSPE, $0.6 \%$ SDS solution with random-primed ${ }^{32} \mathrm{P}$-labeled probes (using the Prime-It II Random Primer Labeling Kit, 
Stratagene). The highest stringency wash was $0.1 \times$ SSPE, $0.6 \%$ $\mathrm{SDS}$, at $66^{\circ} \mathrm{C}$. A $1.4-\mathrm{kb} \mathrm{XbaI}-\mathrm{SpeI}$ genomic fragment which produced a mei-2-like RNAi phenotype was used as the mei-2 probe (see Fig. 1C). The blot was probed simultaneously with a ribosomal protein gene $(r p 21$, kindly provided by J. Spieth, Indiana University, Bloomington) to quantify RNA levels. RNA was sized by loading one lane with the G319 Molecular Weight Ladder (Promega), which was removed from the gel and stained with ethidium bromide. Exposure of the blots and signal quantification were performed with the Storm PhosphorImager and ImageQuaNT software (Molecular Dynamics). Images were cropped and processed with Adobe Photoshop and Corel Draw software.

\section{Antibodies}

Full-length mei-2 cDNA was obtained by RT-PCR amplification using $5^{\prime}$ and $3^{\prime}$ primers containing linkers for insertion into a HIS-tagged fusion vector (QE30) from the QiaExpression kit (Qiagen). Bacterially expressed protein was purified under denaturing conditions $(8 \mathrm{M}$ urea) by passage through a Ni-NT Agarose column, using manufacturer's protocol. This purified protein was electrophoresed through an SDS-PAGE gel and excised to immunize rabbits (Harlow and Lane 1988). Antiserum (MS$3 \mathrm{~F}$ ) was affinity purified as follows: an amino-terminal portion (residues 2-99) of MEI-2 was fused to GST (Promega), bacterially expressed, and purified under native conditions. Approximately $2 \mathrm{mg}$ of purified GST-MEI-2(2-99) protein was coupled to cyanogen bromide-activated Sepharose (Pharmacia). MS-3F antiserum was applied to the Sepharose column to produce affinity purified antiserum used for all Western blots and immunofluorescence microscopy experiments described herein. Anti-MEI-1 serum was affinity purified as above with an amino-terminal portion (residues 13-217) obtained by inserting an EcoRV-EcoRI mei-1 cDNA fragment into the GST fusion vector. The mouse anti- $\alpha$-tubulin monoclonal antiserum was described in Piperno and Fuller (1985).

\section{Immunoblotting}

For all Western analyses, worms were picked into $5 \mu l$ of $\mathrm{ddH}_{2} \mathrm{O}$ and immediately frozen in a dry ice/ethanol bath. Five $\mu 1$ of $2 x$ SDS-PAGE loading buffer was added to the frozen worms and the resulting mixture was immediately transferred to a boiling water bath for $10 \mathrm{~min}$ prior to loading. One-hundred gravid adult worms were used for each lane except for the ct102 lane [genotype: dpy-5 mei-2(ct102) unc-29] which contained 125 worms because the $d p y-5$ mutation resulted in an approximate $1 / 4$ decrease in the level of signal with the loading control probe, anti- $\alpha$-tubulin. This was likely due to Dpy- 5 worms containing fewer fertilized eggs than wild-type worms. All mei-2 mutants were linked to unc-29 and therefore, Unc-29 worms were used for the wild-type control. The molecular weight of MEI-2 was estimated to be $\sim 33 \mathrm{kD}$ using a protein molecular weight marker that was removed from the blot prior to probing.

After SDS-PAGE, proteins were electrophoretically transferred to PVDF (Millipore) filters (Sambrook et al. 1989). Filters were blocked in blocking buffer: $5 \%$ skim milk in PBS $+0.1 \%$ Tween-20 (PBS-T) overnight at $4^{\circ} \mathrm{C}$, washed with PBS-T and incubated $1 \mathrm{hr}$ with the primary antibody in blocking buffer at room temperature. The filters were then washed $3 \times$ for a total of 30 min with PBS-T and incubated with HRP-coupled secondary antibodies [Sheep anti-mouse (Amersham) at 1/2000 dilution or goat anti-rabbit (Jackson Immunoresearch) at 1/5000 dilution] for $1 \mathrm{hr}$ at $22^{\circ} \mathrm{C}$. After a final round of washes for $30 \mathrm{~min}$, the filters were exposed using chemiluminescence (ECL).

\section{Indirect fluorescence microscopy of embryos and gonads}

Preparation of embryos for immunohistochemistry was performed using the methanol-acetone method of Albertson (1984) and as modified by Kemphues et al. (1986). Gonads were released into Egg buffer (Edgar 1995) by scissoring gravid adults at the head or tail with two 21-gauge needles. Fixation of gonads was performed as above. Affinity purified MEI-2 antiserum (MS3 F) was used at $1 / 100$ dilution. The immunostaining of $\alpha$-tubulin was performed as described by Clark-Maguire and Mains (1994a). Secondary antibodies (at 1/100 dilution) used were either FITC-conjugated Goat anti-rabbit and TRITC-conjugated Goat anti-mouse, or Cy3-conjugated Donkey anti-rabbit and Cy2-conjugated Donkey anti-mouse (Jackson Immunoresearch). Stained embryos were immersed in a $1-\mu \mathrm{g} / \mathrm{ml}$ solution of DAPI $\left(4^{\prime}\right.$, 6-diamidine-2'-phenylindole dihydrochloride) prior to mounting in a $1-\mathrm{mg} / \mathrm{ml}$ solution of $p$-phenylenediamine in $90 \%$ glycerol to reduce fluorescence fading. Photographs were taken with a Zeiss Axioplan fluorescence microscopy camera on Techpan film (Kodak) and developed at ASA100. Photographs in Figure 4C-E were obtained with a Leica DMRE fluorescence microscope and deconvoluted using Vay-Tek software. All images were cropped and processed with Adobe Photoshop and Corel Draw software.

\section{RNAi}

All genomic DNA templates were cloned into the pBluescript $\mathrm{SK}(+)$ vector (Stratagene). Transcription with T7 and T3 RNA polymerases (Pharmacia) was performed directly on linearized template according to the manufacturer's instructions. For F47G4.4 and F47G4.5 RNAi, M13 forward and reverse primers were used to amplify the cloned cDNA, followed by transcription from gel-purified template using T3 and T7 reactions with the Ambion MEGAscript system. After transcription, all DNA templates were digested with DNase I, and the resulting RNAs were purified via standard phenol/chloroform extraction followed by ethanol precipitation. To make dsRNA, RNA from both forward and reverse reactions were mixed in a 1:1 ratio (100 ng/ $\mu \mathrm{l} \mathrm{each),} \mathrm{denatured} \mathrm{at} 95^{\circ} \mathrm{C}$, and allowed to reanneal by slow cooling for $\sim 10 \mathrm{~min}$. All RNAs were injected into the syncytial gonad of young N2 hermaphrodite adults, which were allowed to recover at $20^{\circ} \mathrm{C}$ for several hours. Embryos from animals that laid dead eggs were analyzed further by dissection and mounting on $5 \%$ agar pads for Nomarski photomicroscopy. Embryos were flash-photographed on a Zeiss Axioplan microscope with Techpan film (Kodak) developed at ASA100.

\section{Identification of mei-2 using RNAi}

F57B10.4 (GenBank accession no. AAB96721), a gene predicted by Genefinder (Green 1995; C. elegans Sequencing Consortium 1998) showed similarity to the human centromere-associated motor protein, CENP-E (Yen et al. 1992), and weak similarity to a rat coiled-coil-related protein that associates specifically with male meiotic chromosomes, SCP1 (synaptonemal complex protein 1; Meuwissen et al. 1992). A 4.8-kb XbaI genomic clone containing F57B10.4 was used as a template for in vitro transcription (Fig. 1C). When RNA from this clone was injected into wild-type hermaphrodites, F1 embryos often had grossly enlarged polar bodies, a phenotype typical of mei-2 mutant embryos (Fig. 1B). A smaller gene, F57B10.12, was also predicted within this genomic clone, in the opposite orientation to the putative CENP-E-like gene. A 1.4-kb XbaI-SpeI subclone that only contained F57B10.12 produced the mei-2 phenotype, whereas a second $1.3-\mathrm{kb}$ SacI-EcoRI subclone that contained only F57B10.4 gave no obvious phenotype (Fig. 1C). 


\section{Transfection of HeLa cells}

For expression of GFP fusion proteins in HeLa cells, full-length cDNAs encoding human p60 katanin or MEI- 1 and the coding sequence of VPS4 were each inserted into the vector pEGFP-C1 (Clontech, ŸethoPalo Alto, CA). Plasmids expressing GST fusions with MEI-2, the con80 domain of human p80 katanin, F47G4.4, and F47G4.5 were produced by performing a threeway ligation of restriction fragments containing coding sequences of GST and the respective coding sequence with a linearized vector (pFM219, a custom Epstein Barr Virus-based vector).

HeLa cells were grown at $37^{\circ} \mathrm{C}$ in Optimem medium (Life Technologies, Rockville, MD) containing 10\% FBS, 50 I.U./ml penicillin, $50 \mu \mathrm{g} / \mathrm{ml}$ streptomycin and were transfected with Lipofectamine Plus reagent (Life Technologies).

\section{Glutathione sepharose binding assays}

To monitor association of GFP-MEI-1 with cotransfected GSTfusion proteins, HeLa cells were transfected in 60-mm dishes. Twenty-four hrs after transfection, cells were washed in PBS, then lysed by addition of $1 \mathrm{ml}$ of lysis buffer [100 mM K-HEPES (pH 7.4), $200 \mathrm{~mm} \mathrm{NaCl}, 1 \mathrm{~mm}$ EGTA, 10\% glycerol, 0.5\% Nonidet $\mathrm{P} 40$ (NP40)(v/v), $200 \mu \mathrm{g} / \mathrm{ml}$ benzamidine, $5 \mathrm{~mm}$ dithiothreitol (DTT), $200 \mu \mathrm{g} / \mathrm{ml} \mathrm{N \alpha -p-tosyl-L-arginine} \mathrm{methyl} \mathrm{ester}$ (TAME), $100 \mu \mathrm{g} / \mathrm{ml} \mathrm{N}$-tosyl-L-phenylalanine chloromethyl ketone (TPCK), $0.5 \mathrm{~mm}$ phenylmethylsufonyl fluoride (PMSF)]. Lysates were cleared by centrifugation at $11,000 \mathrm{~g}$ for $20 \mathrm{~min}$. Supernatants $(1 \mathrm{ml})$ were added to $75 \mu \mathrm{l}$ of packed glutathione sepharose 4B (Pharmacia, Piscataway, NJ) and agitated for $2 \mathrm{hr}$ with gentle rocking at $4^{\circ} \mathrm{C}$. Resin was recovered by brief centrifugation and then washed $4 \times$ each, with $\sim 15$ volumes of cold lysis buffer. One hundred $\mu \mathrm{l}$ of Laemmli SDS sample buffer was added directly to the resin and the sample was heated for $5 \mathrm{~min}$ at $75^{\circ} \mathrm{C}$. Unbound supernatants and eluted glutathione-binding fractions were then subjected to analysis by SDS-PAGE and immunoblotting.

\section{Microtubule disassembly in transfected HeLa cells}

HeLa cells were grown on coverslips and fixed in $-20^{\circ} \mathrm{C}$ methanol $24 \mathrm{hr}$ after transfection. Methanol-fixed cells on coverslips were washed briefly in PBS, and then treated with blocking buffer (4\% BSA, $0.05 \%$ Triton $\mathrm{X}-100$ and $0.1 \% \mathrm{NaN}_{3}$ in PBS) for $1 \mathrm{hr}$ at $25^{\circ} \mathrm{C}$. Coverslips were incubated $1-2 \mathrm{hrs}$ with $1 / 1000$ anti- $\alpha$-tubulin (DM1 $\alpha$; Sigma, St. Louis, MO) in blocking buffer at $25^{\circ} \mathrm{C}$ and then washed $4 \times$ for $15 \mathrm{~min}$ with washing buffer. Coverslips were incubated $1-2 \mathrm{hrs}$ with $2 \mu \mathrm{g} / \mathrm{ml}$ DAPI and 1/1000 goat anti-mouse IgG Alexa 594 conjugate (Molecular Probes, Eugene, OR) in blocking buffer, then washed again before mounting.

Images were acquired with a Nikon Microphot-SA microscope, a 60× PlanApo NA1.4 objective, and a Quantix KAF1400 CCD camera (Photometrics, Tucson, AZ) controlled by IP Lab Spectrum software (Scanalytics, Fairfax, VA). GFP and anti-tubulin immunofluorescence images were recorded for each selected field using exposure times that resulted in a maximal pixel value of 3000-4000 (saturation value 4095) for each image. Within an image, transfected cells were identified by GFP fluorescence, and the intensity of fluorescence was quantified (described below) for the transfected cell and 4-6 neighboring untransfected cells. The procedure was repeated to measure the fluorescence intensity of anti-tubulin staining for the same transfected and untransfected cells. The ratio of fluorescence intensity of the transfected cell to the average intensity of the untransfected cells was calculated for GFP and immunostained MTs; these values are plotted in Figure 9B-G. Fluorescence intensity of each cell was measured by first drawing an irregularly shaped region within the interphase cell (avoiding the nucleus and out-of-focus areas), measuring the average pixel intensity within that region, and then adjusting that intensity value by subtracting the measured average pixel intensity for 2-3 background regions devoid of any cells or debris.

\section{Acknowledgments}

We thank T. Clandinin and S. Clark-Maguire for early work on this project, F. Allen for purification of the MEI- 1 antiserum, J. McGhee, W. Brook, and members of the Mains laboratory for critical reading of the manuscript. We are also grateful to $\mathrm{C}$. Shelton and B. Bowerman for telling us about a mei-2 cDNA that they identified in an unrelated project. We also thank $\mathrm{T}$. Stiernagle of the Caenorhabditis elegans Genetics Center (St. Paul, MN) for providing many of the strains used in this study and A. Coulson of the Sanger Centre (Cambridge, UK) for providing cosmids. This work was supported by a studentship from the Alberta Heritage Foundation for Medical Research to M.S., by grants from the Medical Research Council of Canada and the Alberta Heritage Foundation for Medical Research to P.E.M., and National Institutes of Health grant GM53060 to F.J.M.

The publication costs of this article were defrayed in part by payment of page charges. This article must therefore be hereby marked "advertisement" in accordance with 18 USC section 1734 solely to indicate this fact.

\section{References}

Afshar, K., N.R. Barton, R.S. Hawley, and L.S.B. Goldstein. 1995. DNA binding and meiotic chromosomal localization of the Drosophila nod kinesin-like protein. Cell 81: 129-138.

Ahmad, F.J., W. Yu, F.J. McNally, and P.W. Baas. 1999. An essential role for katanin in severing microtubules in the neuron. J. Cell Biol. 145: 305-315.

Albertson, D.G. 1984. Formation of the first cleavage spindle in nematode embryos. Dev. Biol. 101: 61-72.

Albertson, D.G. and J.N. Thomson. 1993. Segregation of holocentric chromosomes at meiosis in the nematode, Caenorhabditis elegans. Chromosome Research 1: 15-26.

Altschul, S.F., W. Gish, W. Miller, E.W. Myers, and D.J. Lipman. 1990. Basic local alignment search tool. J. Mol. Biol. 215: 403-410.

Austin, J. and J. Kimble. 1987. glp-1 is required in the germ line for regulation of the decision between mitosis and meiosis in C. elegans. Cell 51: 589-599.

Babst, M., T.K. Sato, L.M. Banta, and S.D. Emr. 1997. Endosomal transport function in yeast requires a novel AAA-type ATPase, Vps4p. EMBO J. 16: 1820-1831.

Barton, M.K., T. Schedl, and J. Kimble. 1987. Gain-of-function mutations of fem-3, a sex-determination gene in Caenorhabditis elegans. Genetics 115: 107-119.

Brenner, S. 1974. The genetics of Caenorhabditis elegans. Genetics 77: 71-94.

C. elegans Sequencing Consortium. 1998. Genome sequence of the nematode C. elegans: A platform for investigating biology. Science 282: 2012-2018.

Clandinin, T.R. and P.E. Mains. 1993. Genetic studies of mei-1 gene activity during the transition from meiosis to mitosis in Caenorhabditis elegans. Genetics 134: 199-210. 
Clark-Maguire, S. and P.E. Mains. 1994a. mei-1, a gene required for meiotic spindle formation in Caenorhabditis elegans, is a member of a family of ATPases. Genetics 136: 533-546.

Clark-Maguire, S. and P.E. Mains. 1994b. Localization of the mei-1 gene product of Caenorhabditis elegans, a meioticspecific spindle component. J. Cell Biol. 126: 199-209.

Cleveland, D.W., M.A. Lopata, P. Sherline, and M. Irschner. 1981. Unpolymerized tubulin modulates the level of tubulin mRNAs. Cell 25: 537-546.

Dow, M.R. and P.E. Mains. 1998. Genetic and molecular characterization of the Caenorhabditis elegans gene, mel-26, a post-meiotic negative regulator of MEI-1, a meiotic-specific spindle component. Genetics 150: 119-128.

Edgar, L.G. 1995. Blastomere culture and analysis. In Caenorhabditis elegans: Modern biological analysis of an organism (ed. H.F. Epstein and D.C. Shakes), pp. 303-321. Academic Press, San Diego, CA.

Fire, A., D.G. Albertson, S.W. Harrison, and D.G. Moerman. 1991. Production of antisense RNA leads to effective and specific inhibition of gene expression in C. elegans. Development 113: 503-514.

Fire, A., S. Xu, M.K. Montgomery, S.A. Kostas, S.E. Driver, and C.C. Mello. 1998. Potent and specific genetic interference by double-stranded RNA in Caenorhabditis elegans. Nature 391: 806-811.

Gard, D.L. 1992. Microtubule organization during maturation of Xenopus oocytes: Assembly and rotation of the meiotic spindle. Dev. Biol. 151: 516-530.

Green, P. 1995. Genefinder Documentation. http://www.ibc.wustl.edu/bio_data/genefinder.html.

Guo, S. and K.J. Kemphues. 1995. par-1, a gene required for establishing polarity in C. elegans embryos, encodes a putative Ser/Thr kinase that is asymmetrically distributed. Cell 81: 611-620.

Harlow, E. and D. Lane. 1988. Antibodies: A laboratory manual. Cold Spring Harbor Laboratory Press, Cold Spring Harbor, New York.

Hartman, J.J., J. Mahr, K. McNally, K. Okawa, A. Iwamatsu, S. Thomas, S. Cheesman, J. Heuser, R.D. Vale, and F.J. McNally. 1998. Katanin, a microtubule-severing protein, is a novel AAA ATPase that targets to the centrosome using a WD40-containing subunit. Cell 93: 277-287.

Huang, X.Y. and D. Hirsh. 1989. A second trans-spliced RNA leader sequence in the nematode Caenorhabditis elegans. Proc. Natl. Acad. Sci. 86: 8640-8644.

Kelly, W.G., S. Xu, M.K. Montgomery, and A. Fire. 1997. Distinct requirements for somatic and germline expression of a generally expressed Caenorhabditis elegans gene. Genetics 146: $227-238$.

Kemphues, K.J., N. Wolf, W.B. Wood, and D. Hirsh. 1986. Two loci required for cytoplasmic organization in early embryos of Caenorhabditis elegans. Dev. Biol. 113: 449-460.

Kirschner, M. and T.J. Mitchison. 1986. Beyond self assembly: From microtubules to morphogenesis. Cell 45: 329-342.

Krause, M. and D. Hirsh. 1987. A trans-spliced leader sequence on actin mRNA in C. elegans. Cell 49: 753-761.

Lohret, T.A., F.J. McNally, and L.M. Quarmby. 1998. A role for katanin-mediated axonemal severing during Chlamydomonas deflagellation. Mol. Biol. Cell 9: 1195-1207.

Mains, P.E., K.J. Kemphues, S.A. Sprunger, I.A. Sulston, and W.B. Wood. 1990. Mutations affecting the meiotic and mitotic divisions of the early Caenorhabditis elegans embryo. Genetics 126: 593-605.

Matthews, L.R., P. Carter, D. Thierry-Mieg, and K. Kemphues. 1998. ZYG-9, a Caenorhabditis elegans protein required for microtubule organization and function, is a component of meiotic and mitotic spindle poles. J. Cell Biol. 141: 11591168 .

Matthies, H.J.G., R. McDonald, L.S.B. Goldstein, and W.E. Theurkauf. 1996. Anastral meiotic spindle morphogenesis: Role of the non-claret disjunctional kinesin-like protein. I. Cell Biol. 134: 455-464.

McKim, K.S. and A.M. Rose. 1990. Chromosome I duplications in Caenorhabditis elegans. Genetics 124: 115-132.

McNally, K.P., O.A. Bazirgan, and F.J. McNally. 2000. Two domains of p80 katanin regulate microtubule severing and spindle pole targeting by p60 katanin. J. Cell Sci. (in press).

McNally, F.J., K. Okawa, A. Iwamatsu, and R.D. Vale. 1996. Katanin, the microtubule-severing ATPase, is concentrated at centrosomes. J. Cell Sci. 109: 561-567.

McNally, F.J. and S. Thomas. 1998. Katanin is responsible for the M-phase microtubule-severing activity in Xenopus eggs. Mol. Biol. Cell 9: 1847-1861.

McNally, F.J. and R.D. Vale. 1993. Identification of katanin, an ATPase that severs and disassembles stable microtubules. Cell 75: 419-429.

Mello, C.C., J.M. Kramer, D. Stinchcomb, and V. Ambros. 1991. Efficient gene transfer in C. elegans: Extrachromosomal maintenance and integration of transforming sequences. EMBO J. 10: 3959-3970.

Merdes, A. and D.W. Cleveland. 1997. Pathways of spindle pole formation: Different mechanisms; conserved components. $J$. Biol. Chem. 138: 953-956.

Meuwissen, R.L.J., H.H. Offenberg, A.J.J. Dietrich, A. Riesewijk, M. van Iersel, and C. Heyting. 1992. A coiled-coil related protein specific for synapsed regions of meiotic prophase chromosomes. EMBO T. 11: 5091-5100.

Montgomery, M.K., S. Xu, and A. Fire. 1998. RNA as a target of double-stranded RNA-mediated genetic interference in Caenorhabditis elegans. Proc. Nat1. Acad. Sci. 95: 15502-15507.

Nelson, G.A., K.K. Lew, and S. Ward. 1978. Intersex, a temperature-sensitive mutant of the nematode C. elegans. Dev. Biol. 66: 386-409.

Patel, S. and M. Latterich. 1998. The AAA team: Related ATPases with diverse functions. Trends Cell Biol. 8: 65-71.

Piperno, G. and M.T. Fuller. 1985. Monoclonal antibodies specific for an acetylated form of $\alpha$-tubulin recognize the antigen in cilia and flagella from a variety of organisms. J. Cell Biol. 101: 2085-2094.

Sambrook, J., E.F. Fritsch, and T. Maniatis. 1989. Molecular cloning: A laboratory manual. Cold Spring Harbor Laboratory Press, Cold Spring Harbor, NY.

Sawada, T. and G. Schatten. 1988. Microtubules in ascidian eggs during meiosis, fertilization, and mitosis. Cell Motil. Cytoskeleton 9: 219-230.

Schatten, G. 1994. The centrosome and its mode of inheritance: The reduction of the centrosome during gametogenesis and its restoration during fertilization. Dev. Biol. 165: 299-335.

Strome, S. and W.B. Wood. 1983. Generation of asymmetry and segregation of germ-line granules in early C. elegans embryos. Cell 35: 15-25.

Theurkauf, W.E. and R.S. Hawley. 1992. Meiotic spindle assembly in Drosophila females: Behaviour of nonexchange chromosomes and the effects of mutations in the nod kinesinlike protein. J. Cell Biol. 116: 1167-1180.

Tournebize, R., R. Heald, and A.A. Hyman. 1997. Role of chromosomes in assembly of meiotic and mitotic spindles. Prog. Cell Cyc. Res. 3: 271-284.

Vale, R.D. 1991. Severing of stable microtubules by a mitotically activated protein in Xenopus egg extracts. Cell 64: 827839.

Vernos, I., J. Raats, T. Hirano, J. Heasman, E. Karsenti, and C. 
Srayko et al.

Wylie. 1995. Xklp1, a chromosomal Xenopus kinesin-like protein essential for spindle organization and chromosome positioning. Cell 81: 117-127.

Walczak, C.E., I. Vernos, T.J. Mitchison, E. Karsenti, and R. Heald. 1998. A model for the proposed roles of different microtubule-based motor proteins in establishing spindle bipolarity. Curr. Biol. 8: 903-913.

Wang, S.Z. and R. Adler. 1995. Chromokinesin: A DNA-binding, kinesin-like nuclear protein. J. Cell Biol. 128: 761-768.

Williams, B.D. 1995. Genetic Mapping. In Caenorhabditis elegans: Modern biological analysis of an organism. (ed. H.F. Epstein and D.C. Shakes), p. 91-93. Academic Press, San Diego, CA.

Wood, W.B. 1988. The nematode Caenorhabditis elegans. Cold Spring Harbor Laboratory Press, Cold Spring Harbor, NY.

Yen, T.J., G. Li, B.T. Schaar, I. Szilak, and D.W. Cleveland. 1992. CENP-E is a putative kinetochore motor that accumulates just before mitosis. Nature 359: 536-539. 


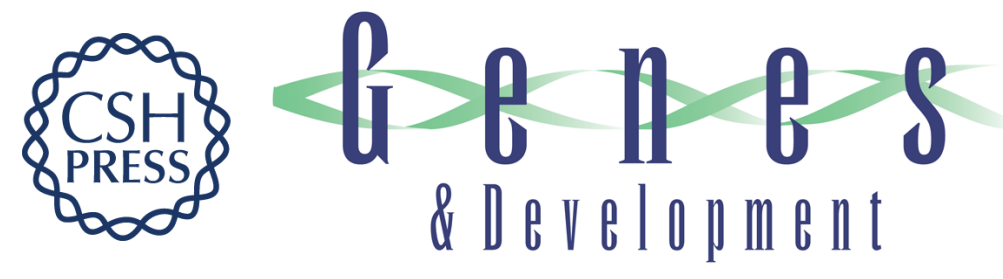

\section{$\mathrm{MEI}-1 / \mathrm{MEl}-2$ katanin-like microtubule severing activity is required for Caenorhabditis elegans meiosis}

Martin Srayko, Dan W. Buster, Omar A. Bazirgan, et al.

Genes Dev. 2000, 14:

Access the most recent version at doi:10.1101/gad.14.9.1072

References This article cites 50 articles, 23 of which can be accessed free at: http://genesdev.cshlp.org/content/14/9/1072.full.html\#ref-list-1

License

Email Alerting

Receive free email alerts when new articles cite this article - sign up in the box at the top Service right corner of the article or click here.

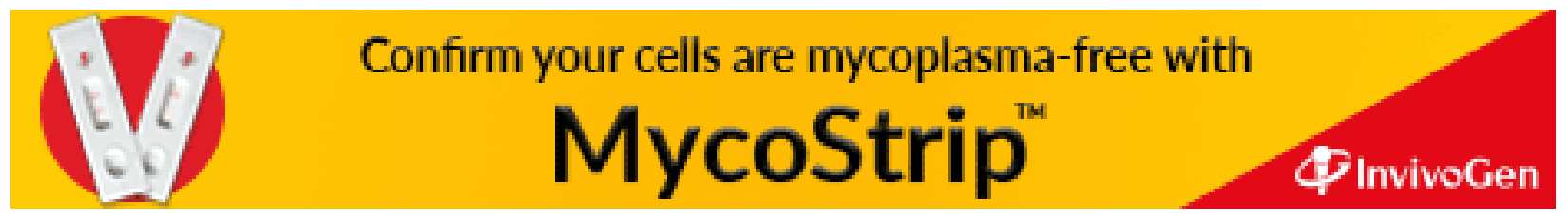

